Canadian

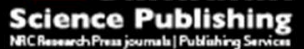

Canadian Journal of Civil Engineering Revue canadienne de génie civil

\title{
Investigation of Significant Inputs for Pavement Rehabilitation Design in the Pavement M-E
}

\begin{tabular}{|r|l|}
\hline Journal: & Canadian Journal of Civil Engineering \\
\hline Manuscript ID & cjce-2017-0046.R3 \\
\hline Manuscript Type: & Article \\
\hline Date Submitted by the Author: & $29-$ Nov-2017 \\
\hline Complete List of Authors: & $\begin{array}{l}\text { Harsini, Iman; Michigan State University, Civil and Environmental } \\
\text { Haider, Syed; Michigan State University, Civil and Environmental } \\
\text { Engineering } \\
\text { Brink, Wouter; Applied Research Associates, Inc. } \\
\text { Buch, Neeraj; Michigan State University, Civil and Environmental } \\
\text { Chatti, Karim; Michigan State University, Civil and Environmental }\end{array}$ \\
\hline $\begin{array}{r}\text { Is the invited manuscript for } \\
\text { consideration in a Special } \\
\text { Issue? : }\end{array}$ & N/A \\
\hline Keyword: & $\begin{array}{l}\text { Pavement-ME, ANN, Pavement Rehabilitation, Sensitivity Analysis, } \\
\text { Interactive Effect }\end{array}$ \\
\hline & \\
\hline \multicolumn{2}{|c}{} \\
\hline
\end{tabular}

SCHOLARONE ${ }^{\text {m }}$

Manuscripts 
Harsini, Haider, Brink, Buch and Chatti

\author{
Iman Harsini ${ }^{1}$ (Corresponding Author) \\ Graduate Research Assistant \\ e-mail: harsinii@egr.msu.edu \\ Syed Waqar Haider ${ }^{1}$, Ph.D., P.E. \\ Assistant Professor \\ e-mail: syedwaqa@egr.msu.edu \\ Wouter C. Brink ${ }^{2}$, Ph.D. \\ Staff Civil Engineer at ARA \\ e-mail: brinkwou@egr.msu.edu \\ Neeraj Buch ${ }^{1}$, Ph.D., FACI \\ Professor \\ buch@egr.msu.edu \\ Karim Chatti ${ }^{1}$, Ph.D. \\ Professor \\ e-mail: chatti@egr.msu.edu \\ ${ }^{1}$ Department of Civil and Environmental Engineering \\ Michigan State University, Engineering Building \\ 428 S. Shaw Lane, Room 3546, East Lansing, MI 48824 \\ Phone: 517-353-9782; Fax: 517-432-1827 \\ ${ }^{2}$ Applied Research Associates \\ 100 Trade Center Dr \#200, Champaign, IL 61820 \\ Phone: 217 - 356 - 4500
}

No. of figures $=2 \times 250=500$ word equivalents

No. of tables $=10 \times 250=2,500$ word equivalents

Text $=5,172$ words

Total $=8,172$ words 
Harsini, Haider, Brink, Buch and Chatti

\section{Investigation of Significant Inputs for Pavement Rehabilitation Design in the Pavement M-E}

\section{ABSTRACT}

42 The Pavement-ME can design different flexible or rigid pavements rehabilitation scenarios. A set

43 of quantitative and qualitative input variables are considered to characterize the new and existing

44 pavement layers and predict the damage accumulation in these layers. To evaluate the impact of

45 the inputs on the predicted performance for the rehabilitation options, sequential analyses were

46 performed to assess the main and interactive effects of each input. Continuous responses surface

47 models for interactive effects were obtained using Artificial Neural Network (ANN).

48 Furthermore, a normalized sensitivity index was used to quantify the significance of main and

49 interactive effects.

50 The following rehabilitation options were included in this paper: HMA over HMA, HMA

51 over JPCP, HMA over fractured JPCP, and JPCP over JPCP. The results of the study can assist

52 the highway agencies' efforts to implementing the Pavement-ME, especially when the most of

53 pavement designs are related to rehabilitation of the existing highways.

54 Keywords: Pavement Rehabilitation, Pavement-ME; ANN; Sensitivity Analysis; Interactive 
Harsini, Haider, Brink, Buch and Chatti

\section{INTRODUCTION}

57 Different rehabilitation options are considered in the Pavement-ME. While the AASHTO 1993

58 Design Guide requires limited information for the structural design of pavements, the Pavement-

59 ME requires a large number of design inputs related to layer materials, environment, and traffic

60 loadings. For each rehabilitation option a large number of input variables (i.e., more than 100) in

61 some cases are required to characterize the new and existing pavement layers. These input

62 variables are categorized into three groups referred to as 'levels' in the Pavement-ME. The

63 engineer chooses between the three levels depending on the data availability (NCHRP Project 1-

64 37A 2004; NCHRP Project 1-40B 2009). Level 1 category is selected when the project specific

65 materials, traffic and climatic data are available. Level 3 category is selected when the least

66 amount of data are available and regional averages are used. Level 2 category corresponds to

67 obtaining inputs based on established correlations.

68 Ideally all the input variables should be studied together to determine their impacts on the

69 predicted pavement performance (Haider et al. 2008). However, performing such an analysis is

70 not efficient. While several past efforts (Buch et al. 2008; Haider et al. 2008; Kannekanti and

71 Harvey 2005) were focused in determining the critical inputs having significant impact on newly

72 constructed pavement predicted performance, such information is scarcely available for

73 rehabilitation options in the Pavement-ME. While distress prediction models (transfer functions)

74 in new and rehabilitation designs are similar, there are some basic differences in the way the

75 damage is calculated among the pavement layers. For flexible rehabilitation options, the

76 differences are: (i) the location of the pavement layers where damage is calculated (which

77 impacts the predicted alligator cracking magnitude), (ii) hardening of the existing HMA layers

78 due to aging, and (iii) characterization of the existing pavement condition. Also, the reflective 
Harsini, Haider, Brink, Buch and Chatti

cracking is only considered in rehabilitation analyses but not in the new pavement design. Additionally, due to the changes in the existing asphalt layer modulus because of the age hardening over time, rutting and longitudinal cracking and hence IRI are different for the rehabilitation options. For rigid rehabilitation scenarios, the main difference between new and rehabilitated pavement design corresponds to characterizing the existing pavement structure conditions. For unbonded overlays, the asphalt interlayer is used to ensure that that no bond exists between the existing pavement surface and the overlay. The interlayer separates the existing PCC slab from the overlay to prevent existing surface distresses from propagating to the overlay slab. The interlayer material inputs are identical to new HMA layer properties. However, the existing PCC pavement inputs differ as compared to new rigid designs.

Moreover, the dynamic modulus of subgrade reaction $(k)$ is unique to rehabilitation, and overrides the internal calculation of $k$ considering base, subbase and subgrade soil information. For rigid pavement rehabilitation, the existing PCC elastic modulus $(E)$ is the only way to classify the condition of the existing PCC pavement. The existing PCC pavement $E$ should be determined either by testing cores taken from the field or by using back-calculation techniques. Researchers have also investigated the sensitivity of specific parameters, such as Poisson's ratio (Maher and Bennert 2008), material's thermal coefficient, and bituminous binders (Awed et al. 2011; Daniel et al. 2009). Additionally, the effect of climate (Byram et al. 2012; Johanneck and Khazanovich 2010; Li et al. 2010; Qiao et al. 2013) and traffic (Ahn et al. 2009; Khanum et al. 2006; Li et al. 2009) has been reflected in the work of other researchers. However, most of the studies only consider the main effects of input variables on the predicted pavement performance. No combined or interactive effects of input variables have been investigated in past. In addition, the most results of such studies have shown only qualitative 
Harsini, Haider, Brink, Buch and Chatti

102

103

104

105

106

107

108

109

110

sensitivity measure. Therefore, there is a need to identify significant inputs and evaluate the sensitivity of performance prediction models to their main and interactive effects quantitatively for different rehabilitation options (Buch et al. 2013).

The contributions of the research presented in this paper will have several short-term and long-term advantages in implementing the Pavement-ME. The short-term benefits include: (a) recommendations on application of the Pavement-ME for the state specific rehabilitation fixes, (b) a list of the most important inputs and typical values needed for using the Pavement-ME rehabilitation design of both flexible and rigid pavements, (c) relative ranking of the important inputs based on their level of impact on the predicted performance. The long-term benefits will emerge by knowing the (a) a set of recommendations for the type of data needed in the state Pavement Management System (PMS) to support use of the Pavement-ME in the future, and (b) a set of recommendations regarding a comprehensive and systematic database that houses project construction data (materials, layer properties and thicknesses, costs), design information and PMS pavement condition data. The Pavement-ME performance models were calibrated based on the field performance of pavements located in the entire United States and Canada (i.e., LTPP database). Therefore, the use of such performance models for sensitivity analyses will also be applicable to field performance of pavements (Ceylan et al. 2013; Haider et al. 2015, 2016).

\section{METHODOLOGY FOR IDENTIFYING SIGNIFICANT DESIGN INPUTS}

The methodology adopted is this study includes three sequential parts: (a) preliminary evaluation, (b) detailed analyses, and (c) global sensitivity. In the preliminary evaluation, the inputs related to the existing pavement layers were analyzed. Subsequently, the significant inputs were combined with the important variables for the new pavement layer (overlay) identified elsewhere (Buch et al. 2008; Harsini 2013) to conduct the detailed sensitivity analysis. The 
Harsini, Haider, Brink, Buch and Chatti

125 detailed sensitivity assessed the statistical significance of individual and combined (interactions)

126 variable effects for existing and new pavement layers. Finally, the global sensitivity analysis

127 (GSA) was performed based on the results from the detailed sensitivity. The GSA is more robust

128 method for identifying the impact of variables on predicted performance because (a) main and

129 interaction results are based on the entire domain of each input variable rather than some unique

130 input levels, (b) importance of each input can be quantified using the normalized sensitivity

131 index (NSI), and (c) relative importance of each design input can be quantified. A brief

132 description of the analyses is presented next.

\section{Preliminary Evaluation}

134 The Pavement-ME needs a large number of input variables for analysis and design of new

135 pavements and rehabilitation. In order to reduce the number of input variables, a preliminary

136 evaluation was performed. Results of the analysis were used to identify sensitive and non-

137 sensitive inputs for various rehabilitation options for different performance measures. The

138 Pavement-ME inputs in rehabilitation modules can be divided into two categories: (a) variables

139 that are specific to rehabilitation and are not part of new design, and (b) inputs similar to the new

140 pavement design (Buch et al. 2008; Schwartz et al. 2011). As shown in Table 1, the design inputs

141 for characterizing the existing HMA pavement along with the practical ranges for the inputs in

142 Michigan are presented for HMA overlay option. These input ranges were considered after

143 discussions with MDOT and work of other researchers (Bayomy et al. 2011; Buch et al. 2013;

144 Haider et al. 2008; NCHRP Project 1-37A 2004; Orobio 2010; Schwartz et al. 2011).

$145<$ Table 1 Design inputs for HMA over HMA rehabilitation option >

146 In this evaluation, the value of each input was varied for three levels - minimum, base-case, and

147 maximum, while keeping all others at their base-case values. Based on the predicted distresses 
Harsini, Haider, Brink, Buch and Chatti

148 (longitudinal cracking, alligator cracking, total rutting, and IRI), the NSI was calculated for each

149 input-distress combination using Equation (3) as described latter. The inputs were ranked based

150 on the NSI (absolute) magnitude and the same process was repeated for different rehabilitation

151 options.

\section{Detailed Analysis}

153 Detailed analysis determines the statistical significance of the input variables. Since the

154 performance prediction models for rehabilitation module are similar to those for new designs, it

155 can be concluded that the significant input variables related to the overlay (i.e. the new layer) are

156 similar to those for a new pavement design for both flexible and rigid pavements (Buch et al.

157 2008). Therefore, in the detailed sensitivity, both types of input variables (i.e., existing and

158 overlay layers) were considered together to identify the important main and interaction effects.

159 In the detailed analysis, a full factorial matrix was designed including several inputs related to

160 existing and overlay layers for each rehabilitation option. The factorial matrices were used to

161 generate the Pavement-ME performance predictions for each rehabilitation option. Two levels

162 (values) were considered for each input and these levels were based on the ranges from the

163 preliminary evaluation (Buch et al. 2008; Haider et al. 2008). As an example, Table 2 shows the

164 list of inputs considered for HMA over HMA rehabilitation option. Analysis of variance

165 (ANOVA) was performed on the performance data at 20 years for each distress to: (a) obtain the

166 main effects with a specified level of confidence, (b) explore the interactive effects between

167 various input variables, (c) provide conclusions to distinguish between practical and statistical

168 significance. Similar process was used for all the rehabilitation options considered in the study. 
Harsini, Haider, Brink, Buch and Chatti

\section{Global Sensitivity Analysis}

170 The inputs from detailed analysis were considered in this subsequent investigation. GSA

171 evaluates the impact of inputs over their entire range as compared to the above-mentioned

172 evaluations where each input had unique levels and one or two variables were considered at a

173 time. The GSA analysis was conducted for all the rehabilitation options by considering the

174 following steps:

175 1. Define a base case for all the rehabilitation options. The base cases consist of the 176 pavement cross-section, material properties and climate information. These base cases

177 should cover the design practices and climatic conditions in the State of Michigan.

178 2. Determine the ranges of input variables in order to cover the entire problem domain.

179 These input ranges were adopted from detailed analysis.

3. Sample input combinations from the problem domain (a $n$-dimension domain, where ' $n$ ' is the total number of input variables for a rehabilitation option). The Latin hypercube sampling (LHS) procedure was used for this purpose. It is a statistical sampling method for generating samples of plausible collections of parameter values from a multidimensional distribution. Generally, the method is commonly used to reduce the number of runs necessary for simulations to achieve a reasonably accurate random distribution (Harsini 2013; Schwartz et al. 2011).

4. Generate the predicted performance to the sampled inputs from step 3 using the Pavement-ME.

5. Fit response surface models (RSM) to the generated data in step 4. To obtain continuous performance measures rather than the predefined discrete locations, a continuous surface 
Harsini, Haider, Brink, Buch and Chatti should be fitted on these discrete points. Therefore, artificial neural network (ANN) fitting tools were used to fit continuous surfaces.

ANNs used in this paper were conventional two-layer (hidden layer and output layer) feed-

197 forward network. Sigmoid transfer functions were used for all hidden layer neurons while linear 198 transfer functions were employed for the output neurons. Training was accomplished using the 199 Levenberg-Marquardt backpropagation algorithm. Seventy percent (70\%), 15\% and 15\% of the 200 GSA simulations for each distress-climate zone combination were used for training, validation, 201 and independent testing of the trained model, respectively.

202 As mentioned before, the NSI was used as sensitivity metric in this study. This index can be used 203 for a point estimation of sensitivity across a problem domain. The point-normalized sensitivity 204 index $S_{i j k}$ is defined as:

$$
S_{i j k}=\left.\frac{d y_{j}}{d x_{k}}\right|_{i} \frac{x_{k i}}{y_{j i}}
$$

206 where,

$207 \quad x_{k i}$ is the value of input $k$ at point $i$

$208 y_{j i}$ is the value of distress $j$ at point $i$

$\left.209 \frac{d y_{j}}{d x_{k}}\right|_{i}$ is change of distress $\mathrm{j}$ with respect to change in input $\mathrm{k}$ at point $\mathrm{i}$

210

211 Equation (1) can be simplified to:

$$
S_{i j k}=\left.\frac{\frac{d y_{j}}{y_{j}}}{\frac{d x_{k}}{x_{k}}}\right|_{i}
$$


Harsini, Haider, Brink, Buch and Chatti

213 Equation (2) shows that the sensitivity index is a ratio between rates of change in performance

214 measure and design input. In some cases, predicted distress, $y_{j i}$ is close to zero resulting in an

215 artificially large sensitivity. Therefore, to overcome this problem $S_{i j k}$ can be normalized with the

216 design limit for a distress as follows (Schwartz et al. 2011):

$$
N S I=S_{i j k}^{D L}=\frac{\Delta y_{j i}}{\Delta x_{k i}} \times \frac{x_{k i}}{D L_{j}}
$$

218 where,

$219 N S I$ is normalized sensitivity index for design limit at point $\mathrm{i}$ for distress $\mathrm{j}$ and input $\mathrm{k}$

$220 \Delta y_{j i}$ is change in distress $j$ about point $i$

$221 \Delta x_{k i}$ is change in input $k$ about point $i$

$222 \quad x_{k i}$ is the value of input $k$ at point $i$

$223 D L_{j}$ is the design limit for distress $j$

224 The NSI was calculated using Equation (3) for most of the cases. However, for discrete design

225 inputs (for e.g., climate, condition rating, PG grade etc.), a modified equation was implemented

226 to determine the sensitivity index (Schwartz et al. 2011). Equation (4) still considers the design

227 limit as a reference for predicted distresses; it normalizes the change in the performance with

228 respect to the specified design limit for a certain distress if the design input is changed by one

229 category. For example, if by changing PG grade from PG 58-22 to PG 76-28 rutting changes by

2300.7 inches while all other inputs are held constant, the NSI for rutting will be $0.7 / 0.5=1.4$. It

231 should be noted that the difference in the predicted performance between categories should be

232 higher than the threshold to obtain NSI greater than 1 for the input to be significant.

$$
N S I=\left.\frac{\Delta y_{j i}}{D L_{j}}\right|_{\Delta X_{k i}=1 \text { category }}
$$


Harsini, Haider, Brink, Buch and Chatti

234 The NSI for IRI also needs special attention because the lower bound for IRI is non-zero value.

235 The NSI formula for IRI when the design limit is $172 \mathrm{inch} / \mathrm{mile}$ and the initial IRI is $63 \mathrm{inch} / \mathrm{mile}$

236 is expressed as (Schwartz et al. 2011):

$$
N S I=\frac{I R I-63}{172-63}
$$

238 The NSI values can be interpreted as:

- If $\mathrm{NSI}=0$, then there is no change in performance with respect to the change in input,

- If $\mathrm{NSI}=1$, then the rates of change in performance and input are the same,

- If NSI $>1$, the performance rate of change is faster than the rate of change in the input.

243 only explains the main effect of an input for a given distress. Therefore, there was a need to

244 modify the NSI interpretation to explain the interactive effect of two variables for evaluating

245 their joint impact. Equations (6) and (7) were developed to evaluate the NSI of a two-way

246 interaction, where Equation (8) shows the numerical solution for Equation (7).

$$
\left.S_{i j k l m}\right|_{(i, j)}=\frac{\partial^{2} y^{m}}{\partial x^{k} \partial x^{l}} \times\left.\frac{x^{k} x^{l}}{y^{m}}\right|_{(i, j)}
$$

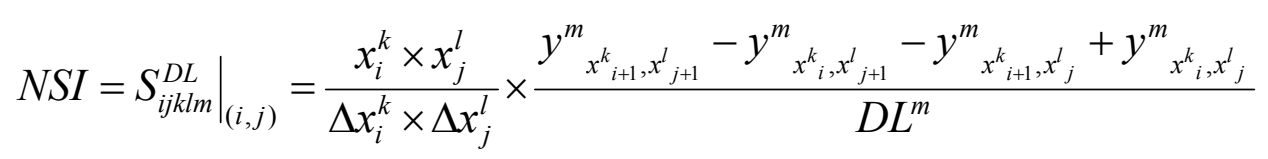

250 where,

$$
\left.S_{i j k l m}^{D L}\right|_{(i, j)}=\begin{aligned}
& \text { sensitivity index for input } k \text { and } l \text {, distress } m \text {, at point }(i, j) \text { with respect to } \\
& \text { design limit }(D L)
\end{aligned}
$$


Harsini, Haider, Brink, Buch and Chatti

$$
\begin{aligned}
x_{i}^{k} & =\text { value of input } x^{k} \text { at point } i \\
x_{j}^{l} & =\text { value of input } x^{l} \text { at point } j \\
\Delta x_{i}^{k} & =\text { change in input } x^{k} \text { around point } i\left(x^{k}{ }_{i+1}-x^{k}{ }_{i-1}\right) \\
\Delta x_{j}^{l} & =\text { change in input } x^{l} \text { around point } j\left(x_{j+1}^{l}-x_{j-1}^{l}\right) \\
y^{m}{ }_{x_{i}{ }_{i}, x_{j}^{l}} & =\text { value of distress } m \text {, for input } x^{k} \text { at point } i \text { and input } x^{l} \text { at point } j \\
D L^{m} & =\text { design limit for distress } m
\end{aligned}
$$

251 Figure 1 summarizes the steps to identify the important design inputs. The number of design

252 inputs and possible interactions between them were narrowed down to a smaller set through

253 preliminary investigation and detailed analysis. In order to cover the entire range of the design

254 inputs, a random sample of the pavement design scenarios are created by using LHS and

255 subsequently, those designs were analyzed through the Pavement-ME to predict pavement

256 performance in the global sensitivity anlaysis. The generated pavement scenarios and the

257 associated performance measures are used to train, verify and validate the neural networks for

258 each performance measure. The trained ANN were used to create the continues pavement

259 performance response curves and surfaces for the design inputs and their interactions,

260 respectively over their entire range. Finally, the design inputs were ranked using the calculated

$261 \quad$ NSI values.

$<$ Fig. 1 The flowchart of methodology used in this investigation $>$

\section{DISCUSSION OF RESULTS}

264 The rehabilitation options typically used by MDOT were considered in this study, which

265 includes: (1) HMA over HMA (HMA overlay), (2) HMA over JPCP (composite), (3) HMA over

266 fractured JPCP (rubblized), and (4) JPCP over JPCP (unbonded overlay). 
Harsini, Haider, Brink, Buch and Chatti

\section{7}

268

269

270

271

272

273

274

275

276

277

278

279

280

281

282

283

284

285

286

287

288

289

\section{Preliminary Evaluation}

Table 3 summarizes the significant inputs from the preliminary evaluation for each rehabilitation option. These inputs only characterize existing pavement. The results show that existing surface layer thickness and existing pavement structural capacity are the most important inputs for all rehabilitation options. It should be noted that only level 3 inputs were used in the preliminary sensitivity analysis. Some of the inputs related to existing layer were not significant based on the preliminary evaluation; however, those were retained in the analysis for investigating interactions in the subsequent analyses. These inputs include: (a) existing PCC thickness and elastic modulus (rubblized), (b) existing PCC flexural strength (composite), and (c) existing PCC modulus (unbonded overlay). Since, the preliminary evaluation was conducted only for inputs related to the existing layers, it is necessary to investigate their potential interactions with inputs related to the overlay layer.

$<$ Table 3 List of significant inputs from preliminary evaluation $>$

\section{Detailed Analysis}

The detailed analyses included the significant variables identified in preliminary evaluation in addition to the significant inputs previously identified for new pavement layers (Buch et al. 2008). Full factorials were designed to determine statistically significant main and two-way interaction effects. Such matrices allow to study the effect of each factor (design inputs) on the response variable (performance measures), as well as the effects of interactions between the levels of the inputs on the response variable. Each cell in the matrices creates a pavement scenario which were used in the Pavement-ME to predict performance for 20 years.

Subsequently ANOVA were performed for each factorial to study the statistical significance of main and interactive (two-way) effects. Those main and interactive effects that were found to be 
Harsini, Haider, Brink, Buch and Chatti

290 significant (within 95\% confidence interval) as shown in Table 4 were included in global 291 sensitivity analyses. $<$ Table 4 List of significant inputs from detailed sensitivity analysis >

\section{Global Sensitivity Analysis}

294 As mentioned before, the statistically significant design input and interactions from detailed 295 analysis are included in global studies. While the extreme values (minimum and maximum) of 296 the input ranges are considered in the detailed analyses, GSA samples from the entire domain for 297 the input ranges to predict performance measures.

298 Four rehabilitation options were considered in GSA similarly to the preliminary and the 299 detailed sensitivity analyses. The main and interactive effect of the design inputs were studied

300 for all pavement performance measures within each rehabilitation option. Tables 5 through 8 301 rank the design input based on the maximum calculated NSI by GSA. The results for HMA over 302 HMA (as presented in Table 5) indicate that, the overlay thickness and HMA volumetrics are the 303 most significant design inputs, especially for longitudinal cracking. The existing thickness and 304 condition rating have an important effect on predicted performances among the inputs related to 305 existing pavement. $<$ Table 5 The Pavement-ME inputs ranking for HMA over HMA >

307 The results for HMA over PCC (see Table 6) show that the overlay thickness and HMA air voids 308 are the most significant inputs for the overlay. Also, the existing PCC thickness has an important 309 effect on longitudinal cracking. For HMA over rubblized PCC rehabilitation option (see Table 7)

310 the HMA thickness, air voids and effective binder content are the most significant inputs for the

311 overlay. The results for unbonded PCC overlay rehabilitation option (see Table 8) show that all 312 overlay related inputs seem to significantly impact the cracking performance. The modulus of 
Harsini, Haider, Brink, Buch and Chatti

313 subgrade reaction ( $k$-value) is the most important variable among all inputs related to the existing

314 layers.

$<$ Table 6 The Pavement-ME inputs ranking for composite pavement $>$ $<$ Table 7 The Pavement-ME inputs ranking for rubblized PCC pavement $>$ $<$ Table 8 The Pavement-ME inputs ranking for unbonded PCC overlay >

318 Tables 9 and 10 rank the interactions between inputs from overlay and existing layer based on

319 the maximum NSI for flexible and rigid rehabilitation options, respectively. The results show 320 that the interaction between overlay air voids and existing pavement thickness seems to be a 321 deciding factor among HMA rehabilitation options. A higher air void in the overlay layers on a 322 thin existing layer seems to be the worst combination for predicted cracking. Additionally, the 323 interaction between overlay thickness and existing PCC layer modulus seems to have the most 324 significant effect on unbonded PCC overlay performance. A thicker overlay may hide the impact 325 of weak existing PCC layer on pavement predicted performance. All the interactions investigated 326 are practically and statistically significant.

$<$ Table 9 Ranking of interactions for different rehabilitation options $>$

329 Figure 2 shows an example of interaction plot for longitudinal cracking between overlay

330 effective binder and HMA existing thickness obtained from the ANN simulations. Figure 2a

331 illustrates that for a thick existing pavement ( $\sim 12$ inch), the predicted longitudinal cracking is

332 negligible regardless of the effective binder content. On the other hand, for a very thin existing

333 pavement (between 4 to 6 inch), the amount of cracking is high regardless of the overlay

334 effective binder content. Therefore, for the pavement structures with the existing HMA thickness

335 between 6 to 10 inch is critical when different overlay effective binder contents are considered. 
Harsini, Haider, Brink, Buch and Chatti

336

337

338

339

340

341

342

343 344 are:

345

346

347

348

349
$<$ Fig. 2 (a) Predicted cracking as result of interaction between exiting thicknesses and overlay effective binder and (b) NSI values >

\section{CONCLUSIONS}

The main objectives of the study were to determine the impact of design inputs on the predicted pavement performance measures for the selected rehabilitation design alternatives in the Pavement-ME. The significant inputs related to material characterization, existing pavement condition, and pavement structure for the rehabilitation options, were identified and ranked based on the NSI. The overarching findings from the analyses performed for different rehabilitation

- HMA over HMA: the overlay thickness and HMA volumetrics (i.e., effective binder content and air voids) are the most significant inputs for the overlay layer while the existing HMA thickness and pavement condition rating have a significant effect on the predicted pavement performance among the inputs related to the existing pavement structure.

- Composite pavements: overlay thickness and HMA air voids are significant inputs for the overlay layer. In addition, among the inputs related to the existing intact PCC pavement, the existing PCC thickness has a significant effect on the predicted pavement performance.

- Rubblized pavements: HMA thickness, air voids and effective binder content are the most significant inputs for the overlay layer. While none of the inputs related to the existing PCC layer have shown a significant impact on the predicted performance, the results show that the existing PCC layer modulus is important for alligator cracking and IRI. 
Harsini, Haider, Brink, Buch and Chatti

- Unbonded overlays: all overlay (i.e. the new layer) related inputs significantly impact the predicted cracking performance while the existing PCC elastic modulus is the most important among inputs related to existing layers.

361 The interaction between overlay air voids and existing pavement thickness significantly impacts

362 all performance measures among HMA rehabilitation options. The interaction between overlay

363 thickness and existing PCC layer modulus has the most significant effect on unbonded overlay

364 predicted performance. It should be noted that all analyses were conducted using input ranges

365 reflecting Michigan practices.

\section{ACKNOWLEDGEMENTS}

367 The authors would like to acknowledge the Michigan Department of Transportation (MDOT) for 368 funding the study.

\section{REFERENCES}

370 Ahn, S., Kandala, S., Uzan, J., and El-Basyouny, M.M. 2009. Comparative analysis of input

371 traffic data and MEPDG output for flexible pavements in state of Arizona. In Transportation

372 Research Board 88th Annual Meeting, Washington DC, United States 11-15 January, 2009.

373 Awed, A., El-Badawy, S.M., Bayomy, P.E., Fouad, M., and Santi, M.J. 2011. Influence of

374 MEPDG binder characterization input level on predicted dynamic modulus for idaho asphalt

375 concrete mixtures. In Transportation Research Board 90th Annual Meeting, Washington DC, 376 United States, 23-27 January, 2011. 
Harsini, Haider, Brink, Buch and Chatti

377 Bayomy, F., El-Badawy, S., and Awed, A. 2011. Implementation of the MEPDG for flexible

378 pavements in Idaho. ITD project RP 194, NIATT Project KLK557. National Institute for

379 Advanced Transportation Technology. University of Idaho, Moscow, Idaho.

380 Buch, N., Chatti, K., Haider, S.W., Baladi, G., Brink, W., and Harsini, I. 2013. Preparation for

381 Implementation of the Mechanistic-Empirical Pavement Design Guide in Michigan: Evaluation

382 of Rehabilitation Fixes Research Report RC-1594. Michigan Department of Transportation,

383 Lansing, MI.

384 Buch, N., Chatti, K., Haider, S.W., and Manik, A. 2008. Evaluation of the 1-37A Design Process

385 for New and Rehabilitated JPCP and HMA Pavements, Final Report Research Report RC-1516.

386 Michigan Department of Transportation, Construction and Technology Division, Lansing, MI.

387 Byram, D., Xiao, D.X., Wang, K.C., and Hall, K.D. 2012. Sensitivity analysis of climatic

388 influence on MEPDG flexible pavement performance predictions. In Transportation Research

389 Board 91st Annual Meeting, Washington DC, United States 22-26 January, 2012.

390 Ceylan, H., Kim, S., Gopalakrishnan, K., and Ma, D. 2013. Iowa Calibration of MEPDG

391 Performance Prediction Models. InTrans Project11-401, Iowa Department of Transportation,

392 Ames, IA.

393 Daniel, J.S., Chehab, G.R., and Ayyala, D. 2009. Sensitivity of RAP binder grade on

394 performance predictions in the MEPDG. Journal of the Association of Asphalt Paving

395 Technologists 78: 325-376.

396 Haider, S.W., Brink, W.C., and Buch, N. 2015. Local calibration of rigid pavement performance

397 models using resampling methods. International Journal of Pavement Engineering 18(7): 1-13. 
Harsini, Haider, Brink, Buch and Chatti

Haider, S.W., Brink, W.C., and Buch, N. 2016. Local calibration of flexible pavement

performance models in Michigan. Canadian Journal of Civil Engineering 43(11): 986-997.

Haider, S.W., Buch, N., and Chatti, K. 2008. Evaluation of M-E PDG for Rigid Pavements-

401 Incorporating the State-of-the-Practice in Michigan. In 9th International Conference on Concrete

402 Pavements San Francisco, California, USA.

403 Harsini, I. 2013. Impact of Design Inputs for Overlay Design in the Mechanistic-Empirical

404 Pavement Desgin Guide. M.Sc. thesis, Department of Civil and Environmental Engineering, 405 Michigan State University, East Lansing, MI.

406 Johanneck, L., and Khazanovich, L. 2010. Comprehensive evaluation of effect of climate in 407 mechanistic-empirical pavement design guide predictions. Transportation Research Record:

408 Journal of the Transportation Research Board, 22(2170):45-55.

409 Kannekanti, V., and Harvey, J. 2005. Sensitivity Analysis of 2002 Design Guide Rigid Pavement

410 Distress Prediction Models. Report No. UCPRC-DG-2006-01. Pavement Research Center, 411 University of California, Davis, University of California, Berkeley.

412 Kannekanti, V., and Harvey, J. 2006. Sensitivity Analysis of 2002 Design Guide JPCP Distress

413 Prediction Models. Transportation Research Record, 1(1947):91-100.

414 Khanum, T., Hossain, M., and Schieber, G. 2006. Influence of Traffic Inputs on Rigid Pavement 415 Design Analysis Using Mechanistic-Empirical Pavement Design Guide. In Transportation 416 Research Board 85th Annual Meeting, Washington DC, United States 22-26 January, 2006. 
Harsini, Haider, Brink, Buch and Chatti

417 Kutay, E., and Jamrah, A. 2012. Preparation for Implementation of the Mechanistic-Empirical

418 Pavement Design Guide in Michigan: Part 1 - HMA Mixture Characterization Research Report

419 ORBP OR10-022. Michigan Department of Transportation, Lansing, MI.

420 Li, J., Pierce, L., Hallenbeck, M., and Uhlmeyer, J. 2009. Sensitivity of axle load spectra in the

421 mechanistic-empirical pavement design guide for Washington state. Transportation Research

422 Record: Journal of the Transportation Research Board, 16(2093):50-56.

423 Li, Q., Wang, K.C., and Hall, K.D. 2010. Verification of virtual climatic data in MEPDG using

424 the LTPP database. International Journal of Pavement Research and Technology, 3(1):10-15.

425 Maher, A., and Bennert, T.A. 2008. Evaluation of Poisson's ratio for use in the mechanistic

426 empirical pavement design guide (MEPDG). Federal Highway Adminstration Report FHWA-

427 NJ-2008-004, Trenton, NJ.

428 NCHRP Project 1-37A. 2004. Guide for Mechanistic-Empirical Design of New and

429 Rehabilitated Pavement structures Final Report. National Cooperative Research Program

430 (NCHRP), Washington D.C.

431 Von Quintus, H. 2009. Local Calibration Guidance for the Recommended Guide for

432 Mechanistic-Empirical Pavement Design of New and Rehabilitated Pavement Structures.

433 NCHRP Project 1-40B, Transportation Research Board, National Research Council,

434 Washington, D.C.

435 Orobio, A. 2010. Sensitivity analysis of flexible pavement performance parameters in the

436 mechanistic-empirical design guide. Ph.D. thesis, Department of Civil and Environmental

437 Engineering, West Virginia University, Morgantown, West Virginia. 
Harsini, Haider, Brink, Buch and Chatti

438 Qiao, Y., Flintsch, G., Dawson, A., and Parry, T. 2013. Examining effects of climatic factors on

439 flexible pavement performance and service life. Transportation Research Record: Journal of the

440 Transportation Research Board, (2349):100-7.

441 Schwartz, C.W., Li, R., Kim, S., Ceylan, H., and Gopalakrishnan, K. 2011. Sensitivity evaluation

442 of MEPDG performance prediction. Final report, NCHRP Project 1-47. Transportation Research

443 Board of the National Academies, Washington, D.C. 
Harsini, Haider, Brink, Buch and Chatti

\section{TABLES}

Table 1 Design inputs for HMA over HMA rehabilitation option.

\begin{tabular}{lccc}
\hline \multicolumn{1}{c}{ Input } & Min & Base-case & Max \\
\hline Existing thickness (in) & 2.5 & 6 & 12 \\
Existing rating & Very poor & Fair & Excellent \\
Milled thickness (in) & 1.5 & 2 & 3.5 \\
Total rutting in existing (in) & 0 & 0.5 & 1 \\
Binder type & Mix 24 & Mix 37 \& 44 & Mix 204 \\
Asphalt mix aggregate gradation & Type 1 & Type 2 & Type 3 \\
\hline
\end{tabular}


Harsini, Haider, Brink, Buch and Chatti

Table 2 List and range of design inputs for HMA over HMA.

\begin{tabular}{|c|c|c|c|c|}
\hline No. & Input variables & Lower limit & Upper limit & Comments \\
\hline 1 & Overlay thickness (inch) (OLTH) & 2 & 8 & $\begin{array}{l}\text { A wider range was used for } \\
\text { sensitivity purposes }\end{array}$ \\
\hline 2 & $\begin{array}{l}\text { Overlay effective binder ( } \% \text { by volume) } \\
\text { (OLEB) }\end{array}$ & 7 & 14 & Reference (Buch et al. 2008) \\
\hline 3 & Overlay PG (OLPG) & PG 58-22 & PG $76-28$ & $\begin{array}{l}\text { Reference (Kutay and Jamrah } \\
\text { 2012) }\end{array}$ \\
\hline 4 & Overlay AV (\%) (OLAV) & 5 & 12 & Reference (Buch et al. 2008) \\
\hline 5 & 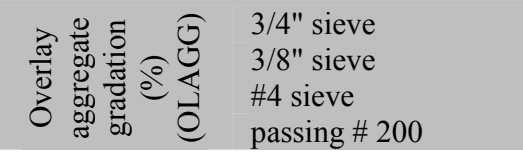 & $\begin{array}{c}100 \\
86.8 \\
79.2 \\
5.6\end{array}$ & $\begin{array}{c}100 \\
88.6 \\
73.2 \\
4.9\end{array}$ & $\begin{array}{l}\text { Reference (Kutay and Jamrah } \\
\text { 2012) }\end{array}$ \\
\hline 6 & Existing condition rating (EXCON) & Very poor & Excellent & $\begin{array}{l}\text { Two possible extremes of the } \\
\text { MEPDG are selected }\end{array}$ \\
\hline $\begin{array}{l}7 \\
8\end{array}$ & \multirow{2}{*}{$\begin{array}{l}\text { Existing HMA thickness (inch) (EXTH) } \\
\text { Existing base modulus (psi) (BMOD) } \\
\text { Existing Sub-base modulus (psi) } \\
\text { (SBMOD) }\end{array}$} & $\begin{array}{c}4 \\
15000\end{array}$ & $\begin{array}{c}12 \\
40000\end{array}$ & $\begin{array}{l}\text { Reference (Buch et al. 2008) } \\
\text { Reference (Buch et al. 2008) }\end{array}$ \\
\hline 9 & & 15000 & 30000 & Reference (Buch et al. 2008) \\
\hline $\begin{array}{l}10 \\
11\end{array}$ & $\begin{array}{l}\text { Subgrade modulus (psi) (SGMOD) } \\
\text { Climate }\end{array}$ & $\begin{array}{l}2500 \\
\text { Pellston }\end{array}$ & $\begin{array}{l}25000 \\
\text { Detroit }\end{array}$ & $\begin{array}{l}\text { Reference (Buch et al. 2008) } \\
\text { Reference (Buch et al. 2008) }\end{array}$ \\
\hline
\end{tabular}


Harsini, Haider, Brink, Buch and Chatti

Table 3 List of significant inputs from preliminary evaluation.

\begin{tabular}{cll}
\hline Rehabilitation option & & \multicolumn{1}{c}{ Significant inputs } \\
\hline HMA over HMA & $\bullet$ & Existing HMA condition rating \\
& $\bullet$ & Existing HMA thickness \\
\hline HMA over JPCP & $\bullet$ & Existing PCC thickness \\
(Composite) & $\bullet$ & Existing PCC flexural strength \\
\hline JPCP over JPCP & $\bullet$ & Existing PCC thickness \\
\hline (Unbonded overlay) & & \\
\hline
\end{tabular}


Harsini, Haider, Brink, Buch and Chatti

Table 4 List of significant inputs from detailed sensitivity analysis

\begin{tabular}{|c|c|}
\hline Rehabilitation option & Significant inputs \\
\hline HMA over HMA & $\begin{array}{ll}\text { - } & \text { Existing HMA condition rating } \\
\text { - } & \text { Existing HMA thickness } \\
\text { - } & \text { Granular base and subgrade modulus } \\
\text { - } & \text { Overlay air voids } \\
\text { - Overlay effective binder } \\
\text { - Overlay binder PG } \\
\text { - Overlay thickness } \\
\end{array}$ \\
\hline $\begin{array}{l}\text { HMA over JPCP } \\
\text { (Composite) }\end{array}$ & $\begin{array}{ll}\text { - } & \text { Existing PCC thickness } \\
\text { - } & \text { Existing PCC flexural strength } \\
\text { - } & \text { Climate } \\
\text { - } & \text { Overlay air voids } \\
\text { - Overlay binder PG } \\
\text { - Overlay thickness } \\
\end{array}$ \\
\hline $\begin{array}{l}\text { HMA over JPCP fractured } \\
\text { (Rubblized) }\end{array}$ & $\begin{array}{l}\text { - } \text { Existing PCC thickness } \\
\text { - } \text { Existing PCC elastic modulus } \\
\text { - Overlay air voids } \\
\text { - Overlay effective binder } \\
\text { - Overlay binder PG } \\
\text { - Overlay thickness }\end{array}$ \\
\hline $\begin{array}{c}\text { JPCP over JPCP } \\
\text { (Unbonded overlay) }\end{array}$ & $\begin{array}{ll}\text { - } & \text { Existing PCC thickness } \\
\text { - } & \text { Existing PCC elastic modulus } \\
\text { - } & \text { Existing modulus of subgrade reaction } \\
\text { - } & \text { Overlay MOR } \\
\text { - Overlay thickness } \\
\text { - Overlay CTE } \\
\text { - Overlay joint spacing } \\
\end{array}$ \\
\hline
\end{tabular}


Harsini, Haider, Brink, Buch and Chatti

Table 5 The Pavement-ME inputs ranking for HMA over HMA

\begin{tabular}{lcccc}
\hline \multirow{2}{*}{\multicolumn{1}{c}{ Design inputs }} & \multicolumn{4}{c}{ Ranking (NSI) } \\
\cline { 2 - 5 } & Alligator cracking & Longitudinal cracking & Rutting & IRI \\
\hline Overlay thickness & $3(0.6)$ & $3(4)$ & $2(0.5)$ & $1(0.65)$ \\
Overlay air voids & $1(1.2)$ & $1(6)$ & $1(0.52)$ & $2(0.51)$ \\
Overlay effective binder & $2(0.7)$ & $5(2)$ & $3(0.47)$ & $4(0.51)$ \\
Existing thickness & $5(0.15)$ & $2(5)$ & $4(0.47)$ & $3(0.51)$ \\
Base modulus & $9(0.05)$ & $8(0.4)$ & $7(0.05)$ & $6(0.44)$ \\
Subbase modulus & $8(0.05)$ & $7(1)$ & $5(0.35)$ & $5(0.45)$ \\
Subgrade modulus & $6(0.1)$ & $6(2)$ & $9(0.05)$ & $7(0.44)$ \\
Existing pavement condition rating & $4(0.5)$ & $4(3.8)$ & $6(0.2)$ & $10(0.05)$ \\
Overlay aggregate gradation & $10(0)$ & $9(0.25)$ & $10(0.05)$ & $8(0.05)$ \\
Overlay PG & $11(0)$ & $11(0)$ & $8(0.05)$ & $11(0.05)$ \\
Climate & $7(0.1)$ & $10(0.05)$ & $11(0.05)$ & $9(0.05)$ \\
\hline
\end{tabular}

Note: The shaded cells show the most important input variables $(|\mathrm{NSI}|>1)$ 
Harsini, Haider, Brink, Buch and Chatti

Table 6 The Pavement-ME inputs ranking for composite pavement

\begin{tabular}{lccc}
\hline \multirow{2}{*}{ Design inputs } & \multicolumn{3}{c}{ Ranking (NSI) } \\
\cline { 2 - 4 } & Longitudinal cracking & Rutting & IRI \\
\hline Overlay thickness & $2(1.8)$ & $2(1)$ & $6(0.56)$ \\
Overlay air voids & $1(8.5)$ & $1(1.75)$ & $3(0.61)$ \\
Overlay effective binder & $7(0)$ & $3(0.7)$ & $2(0.64)$ \\
Overlay PG & $5(0.2)$ & $4(0.6)$ & $7(0.5)$ \\
Overlay aggregate gradation & $9(0)$ & $7(0.1)$ & $8(0.5)$ \\
Existing PCC thickness & $3(1)$ & $5(0.3)$ & $4(0.58)$ \\
Existing PCC modulus & $4(0.25)$ & $6(0.2)$ & $5(0.57)$ \\
Subgrade reaction modulus & $8(0)$ & $9(0)$ & $1(0.75)$ \\
Climate & $6(0.1)$ & $8(0.05)$ & $9(0.5)$ \\
\hline
\end{tabular}


Harsini, Haider, Brink, Buch and Chatti

Table 7 The Pavement-ME inputs ranking for rubblized PCC pavement

\begin{tabular}{lcccc}
\hline \multirow{2}{*}{ Design inputs } & \multicolumn{4}{c}{ Ranking (NSI) } \\
\cline { 2 - 5 } & Alligator cracking & Longitudinal cracking & Rutting & IRI \\
\hline Overlay thickness & $3(1)$ & $5(0.1)$ & $3(0.8)$ & $3(0.85)$ \\
Overlay air voids & $1(4)$ & $1(6)$ & $1(2.8)$ & $1(1)$ \\
Overlay effective binder & $2(2.1)$ & $2(1.2)$ & $2(1.1)$ & $2(0.87)$ \\
Overlay PG & $6(0.05)$ & $7(0.05)$ & $4(0.4)$ & $6(0.84)$ \\
Overlay aggregate gradation & $7(0.05)$ & $8(0.05)$ & $5(0.2)$ & $8(0.84)$ \\
Existing PCC thickness & $5(0.05)$ & $4(0.1)$ & $8(0.1)$ & $4(0.85)$ \\
Existing PCC modulus & $4(0.8)$ & $3(0.4)$ & $6(0.15)$ & $5(0.85)$ \\
Climate & $8(0.05)$ & $6(0.05)$ & $7(0.1)$ & $7(0.84)$ \\
\hline
\end{tabular}

Note: The shaded cells show the most important input variables $(|\mathrm{NSI}|>1)$ 
Harsini, Haider, Brink, Buch and Chatti

Table 8 The Pavement-ME inputs ranking for unbonded PCC overlay

\begin{tabular}{lccc}
\hline \multicolumn{1}{c}{ Design inputs } & \multicolumn{3}{c}{ Ranking (NSI) } \\
& Cracking & Faulting & IRI \\
\hline Overlay PCC thickness (inch) & $1(23)$ & $4(0.4)$ & $2(1.05)$ \\
Overlay PCC CTE (per ${ }^{\circ}$ F x 10-6) & $2(12)$ & $1(1.1)$ & $1(1.2)$ \\
Overlay joint spacing (ft) & $4(5)$ & $2(0.55)$ & $8(0.75)$ \\
Overlay PCC MOR (psi) & $3(8)$ & $5(0.2)$ & $5(0.82)$ \\
Modulus of subgrade reaction (psi/in) & $5(0.5)$ & $8(0.1)$ & $4(0.88)$ \\
Existing PCC thickness (inch) & $8(0.1)$ & $3(0.45)$ & $6(0.81)$ \\
Existing PCC elastic modulus (psi) & $6(1)$ & $7(0.1)$ & $3(1.05)$ \\
Climate & $7(1)$ & $6(0.1)$ & $7(0.8)$ \\
\hline
\end{tabular}

Note: The shaded cells show the most important input variables ( $|\mathrm{NSI}|>1)$ 
Harsini, Haider, Brink, Buch and Chatti

Table 9 Ranking of interactions for different rehabilitation options

\begin{tabular}{lcccc}
\hline \multicolumn{1}{c}{ Interaction } & Alligator cracking & $\begin{array}{c}\text { Ranking (NSI) } \\
\text { Longitudinal cracking }\end{array}$ & Rutting & IRI \\
\hline \multicolumn{1}{c}{ HMA over HMA } & & & & \\
Overlay air voids \& existing thickness & $1(0.8)$ & $1(15)$ & $3(0.3)$ & $3(0.1)$ \\
Overlay eff. binder \& existing thickness & $2(0.5)$ & $3(7)$ & $2(0.3)$ & $2(0.1)$ \\
Overlay thickness \& existing thickness & $3(0.5)$ & $2(10)$ & $1(0.4)$ & $1(0.2)$ \\
\hline$\quad$ HMA over JPCP (composite) & & $2(25)$ & $2(1.5)$ \\
Overlay thickness \& existing thickness & & $1(44)$ & $1(1.7)$ \\
Overlay air voids \& existing thickness & $1(3.7)$ & $1(2.4)$ & $2(0.8)$ & $2(0.1)$ \\
\hline HMA over fractured PCC (rubblized) & $2(2.1)$ & $2(1.1)$ & $1(1)$ & $1(0.1)$ \\
Overlay air voids \& existing thickness & $3(0.8)$ & $3(0.5)$ & $3(0.8)$ & $3(0.1)$ \\
Overlay effective binder \& existing thickness & & & & \\
Overlay thickness \& existing thickness & & &
\end{tabular}


Harsini, Haider, Brink, Buch and Chatti

Table 10 Interaction ranking for unbonded PCC overlay

\begin{tabular}{lccc}
\hline \multicolumn{1}{c}{ Interaction } & Ranking (NSI) & \\
& Cracking & Faulting & IRI \\
\hline Overlay thickness and existing modulus & $1(28.5)$ & $1(0)$ & $1(1.5)$ \\
Overlay MOR and existing thickness & $3(6)$ & $2(0)$ & $3(0.7)$ \\
Overlay MOR and existing modulus & $2(14.5)$ & $3(0)$ & $2(0.7)$ \\
\hline
\end{tabular}


Harsini, Haider, Brink, Buch and Chatti

\section{FIGURE CAPTIONS}

466 Fig. 1. The flowchart of methodology used in this investigation.

467 Fig. 2. (a) Predicted cracking as result of interaction between exiting thicknesses and overlay 468 effective binder and (b) NSI values. 


\begin{tabular}{|c|c|c|c|c|}
\hline $\begin{array}{l}\text { Shortlisting of } \\
\text { Design Inputs }\end{array}$ & $\begin{array}{l}\text { Sampling over } \\
\text { inputs' ranges }\end{array}$ & $\begin{array}{l}\text { ANN } \\
\text { simulations }\end{array}$ & $\begin{array}{l}\text { Performance } \\
\text { response } \\
\text { surfaces }\end{array}$ & $\begin{array}{l}\text { Design inputs } \\
\text { impact }\end{array}$ \\
\hline $\begin{array}{l}\text { - Preliminary evaluation } \\
\text { (existing pavement } \\
\text { inputs) - typical } \\
\text { ranges. } \\
\text { - Detailed analysis } \\
\text { (overlay \& existing } \\
\text { pavement inputs and } \\
\text { interactions between } \\
\text { them by using ANOVA) } \\
\text { - extreme values }\end{array}$ & $\begin{array}{l}\text {-Generating random } \\
\text { Pavement-ME input over } \\
\text { the entire range using } \\
\text { LHS. } \\
\text { - Predicting performance } \\
\text { through Pavement-ME } \\
\text { runs. }\end{array}$ & $\begin{array}{l}\text { - Create and training the } \\
\text { neural network based on } \\
\text { the inputs and predicted } \\
\text { performance } \\
\text { - Verifying the ANN } \\
\text { - Validating the ANN }\end{array}$ & $\begin{array}{l}\text { - Creating continuous } \\
\text { performance response } \\
\text { curves (i.e. pavement } \\
\text { performance) for each } \\
\text { design input using ANN } \\
\text { - Creating continuous } \\
\text { performance response } \\
\text { surface for more than } \\
\text { one variable to } \\
\text { investigate interactions. }\end{array}$ & $\begin{array}{l}\text { - Calculating NSI values } \\
\text { for each design input for } \\
\text { all performance } \\
\text { measures. } \\
\text { - Calculating NSI values } \\
\text { for interactions. }\end{array}$ \\
\hline
\end{tabular}




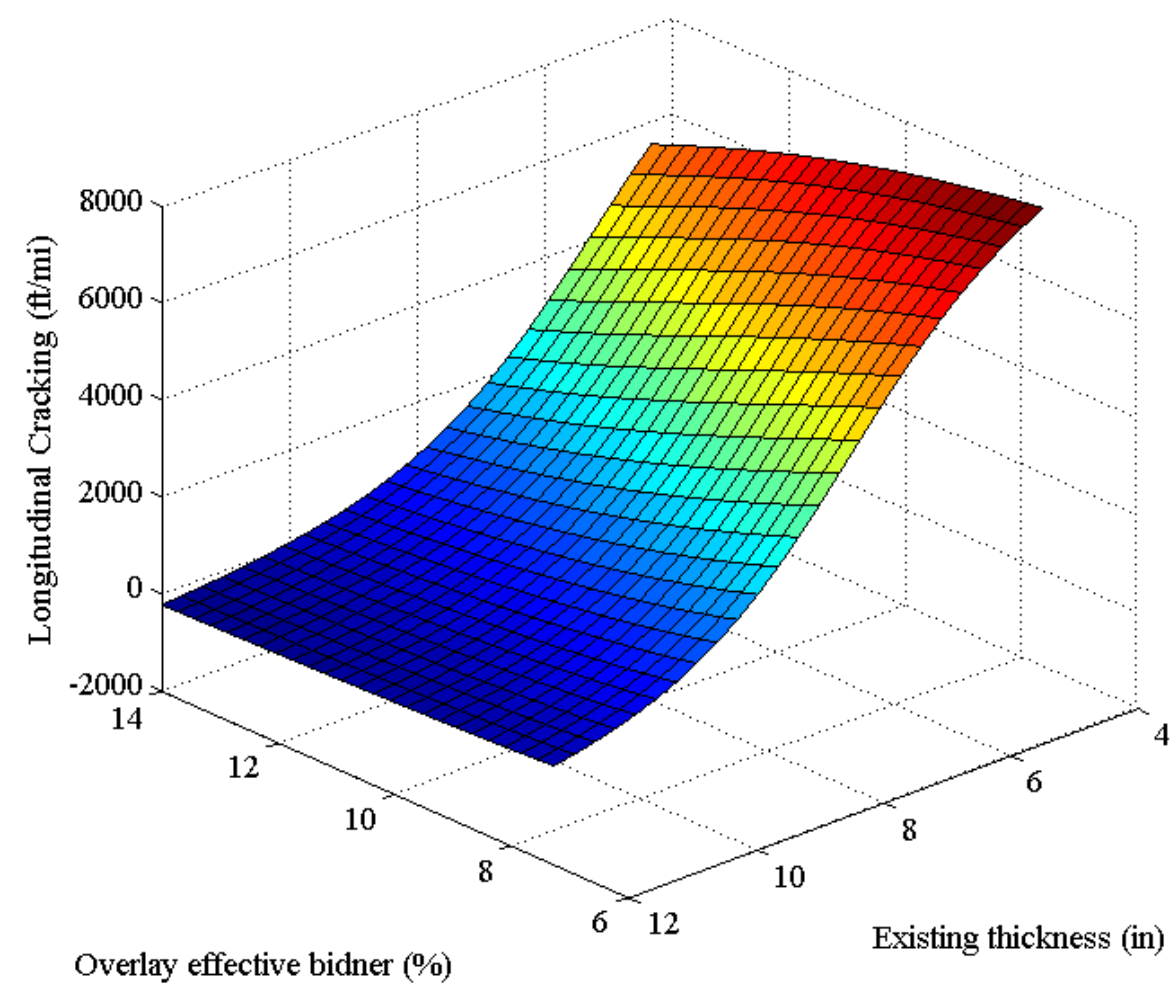

(a)

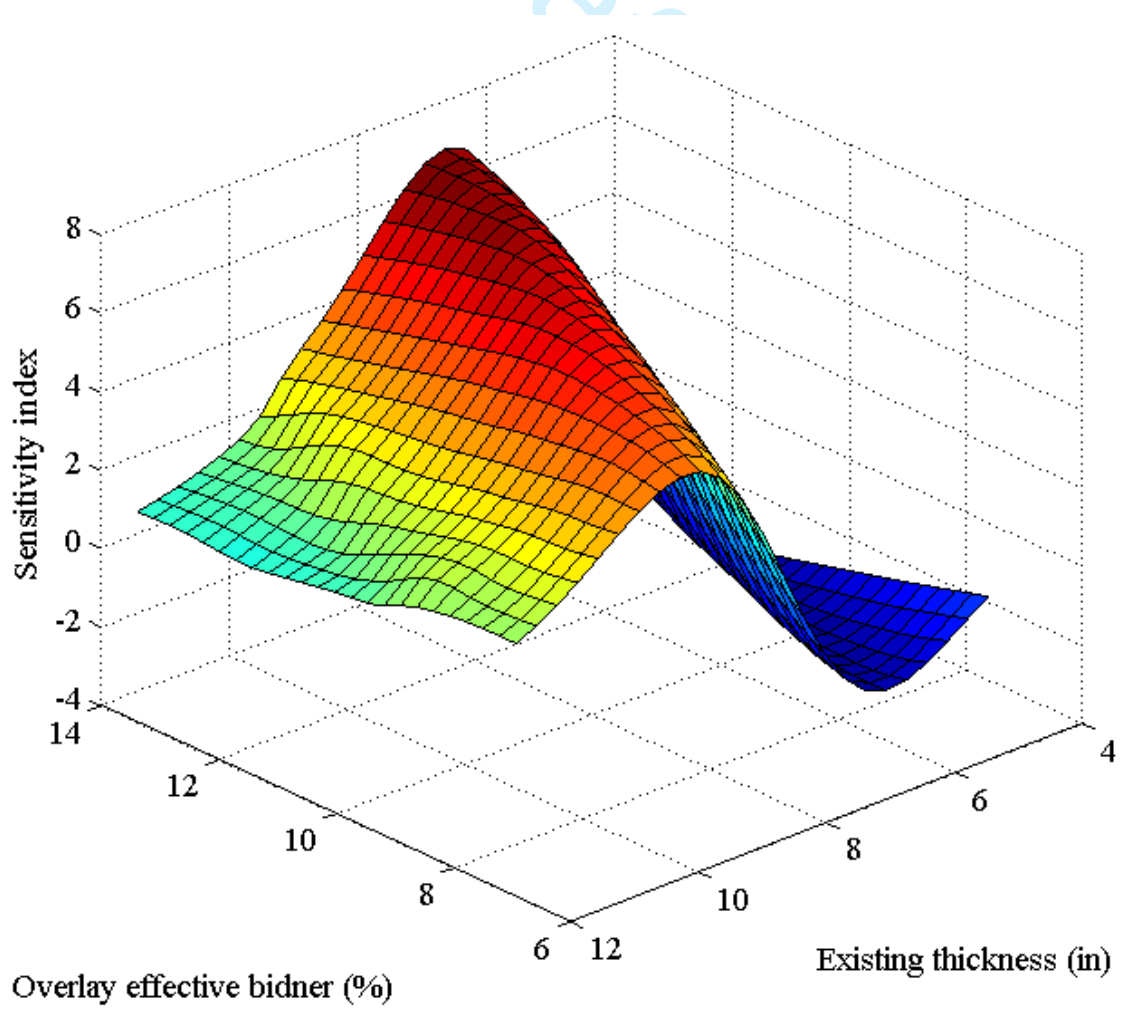

(b) 